\title{
Characterization of a Cellular Immunostimulating Peptide from a Soybean Protein Fraction Digested with Peptidase $R$
}

\author{
Shintaro EGUSA ${ }^{1,2}$ and Hajime OTANI ${ }^{1, *}$ \\ ${ }^{1}$ Interdisciplinary Graduate School of Science and Technology, Shinshu University, Minami-minowa 8304, \\ Kami-ina, Nagano 399-4598, Japan \\ ${ }^{2}$ Marusan-ai Co., Ltd., 1, Arasita, Aza, Nikki-cho, Okazaki, Aichi 444-2193, Japan
}

(Received April 10, 2009)

\begin{abstract}
Summary An immunostimulating glutamine-rich peptide was purified from a soybean protein fraction digested with Peptidase R produced by Rhizopus oryzae (Ro-digest) by a combination of SP-Sepharose column chromatography and reversed-phase high-performance liquid chromatography. The purified peptide was supposed to be located at or near the glutamine-rich region 202 to 222 of the glycinin G4 subunit. The peptide significantly increased the number of $\mathrm{CD}^{+}, \mathrm{CD} 11 \mathrm{~b}^{+}$, and $\mathrm{CD} 49 \mathrm{~b}^{+}$cells in $\mathrm{C} 3 \mathrm{H} / \mathrm{HeN}$ mouse spleen cell cultures, while 2 chemically synthesized glutamine-rich peptides corresponding to residues 202 to 213 (QQQQQQKSHGGR) and residues 214 to 225 (KQGQHQQEEEEE) of the glycinin G4 subunit increased the number of interleukin (IL)- $12^{+} \mathrm{CD}_{11} \mathrm{~b}^{+}$cells. The peptide $202-$ 213 also significantly increased the number of $\mathrm{CD} 49 \mathrm{~b}^{+}$, IL- $2^{+} \mathrm{CD} 4^{+}$, and interferon$\gamma^{+} \mathrm{CD}^{+}$cells and stimulated the cytotoxic activity of spleen cells toward the human erythroleukemia cell line K562. These results indicate that the glutamine-rich region of the soybean glycinin G4 subunit stimulates the cellular immune system in mouse spleen cell cultures.
\end{abstract}

Key Words glycinin G4, Peptidase R, cellular immunostimulation, glutamine-rich peptide, cytotoxic activity

The innate and adaptive responses of the immune system play an important role in host defense against microorganisms. The innate immune response, forming the first line of defense against attacks by pathogens, is mediated by macrophages, dendritic cells (DC), and natural killer (NK) cells. The adaptive immune response is involved in the elimination of pathogens in the late phase of infection and in the generation of immunological memory. Recently, some food proteins and their digests have been demonstrated to modulate the immune system. Ohnuki et al. (1) found that the oral ingestion of cow's milk IgG stimulated the innate cellular immune response and suppressed the humoral adaptive immune responses in mice. Kuhara et al. (2) demonstrated that the oral administration of lactoferrin increased the number of NK cells in peripheral blood and spleen and enhanced interferon (IFN)- $\gamma$ production in mice. Moreover, Otani et al. (3-5) reported that the oral administration of a commercially available casein phosphopeptide (CPP) enhanced mucosal IgA responses in mice and piglets and reduced allergic symptoms through the enhancement of intestinal IgA levels and the reduction of serum IgE levels in NC/Jic Jcl mice. Taken together, some food proteins and their digests may be utilized as anti-infectious and anti-allergic food additives.

Soybeans are known as a source of high-quality pro-

\footnotetext{
* To whom correspondence should be addressed.
}

E-mail: otani84@gipmc.shinshu-u.ac.jp tein because of their well-balanced amino acid composition. Some soybean proteins and their digests have been recently shown to possess immunostimulatory activities. Yoshikawa et al. (6) demonstrated that a peptide corresponding to residues 296 to 301 of the glycinin A1a subunit stimulated phagocytosis in mice, while Tsuruki et al. (7) isolated a phagocytosis-stimulating peptide corresponding to residues 173 to 185 of the $\beta$ conglycinin $\alpha^{\prime}$ subunit.

In our previous study (8), we demonstrated that a peptide mixture obtained from an acid-precipitated soybean protein fraction digested with Peptidase $\mathrm{R}$ produced by Rhizopus oryzae displayed a strong mitogenic activity and increased the number of interleukin (IL)$12^{+} \mathrm{CD} 11 \mathrm{~b}^{+}$, IFN- $\gamma^{+} \mathrm{CD} 49 \mathrm{~b}^{+}$, and IFN- $\gamma^{+} \mathrm{CD} 4^{+}$cells in mouse spleen cell cultures. We also demonstrated that the oral administration of the digest increased the number of spleen IL- $12^{+} \mathrm{CD} 11 \mathrm{~b}^{+}$cells and stimulated the cytotoxic activity of spleen cells toward human erythroleukemia cell line K562 compared to non-administration. Moreover, DNA microarray analysis showed that the gene expression related to the innate immune response in Peyer's patch cells increased in mice given the diet (8). In this study, we characterized an immunostimulating peptide in the soybean protein fraction digested with Peptidase R (Ro-digest).

\section{MATERIALS AND METHODS}

Materials. Defatted soybean seed flour and Peptidase $\mathrm{R}$ were obtained from J-Oil Mills, Inc. (Tokyo, 
Japan), and Amano Enzyme, Inc. (Nagoya, Japan), respectively. Defined fetal bovine serum (FBS) and RPMI-1640 medium were purchased from EquitechBio, Inc. (Kerrville, TX, USA), and Nissui Pharmaceutical (Tokyo, Japan), respectively. Biolegend (San Diego, CA, USA) supplied phycoerythrin (PE)-labeled antimouse IL-2 monoclonal antibodies (mAb, clone JES65H4), PE-labeled anti-mouse IL-4 mAb (clone 11B11), PE-labeled anti-mouse IL-12 IL-23/p40 mAb (clone C15.6), PE-labeled anti-mouse IFN- $\gamma$ mAb (clone XMG1.2), PE-labeled anti-mouse CD49b mAb (clone DX5), biotin-labeled anti-mouse CD8 mAb (clone 536.7), biotin-labeled anti-mouse CD4 mAb (clone RM45), biotin-labeled anti-mouse CD11b mAb (clone M1/ 70), and phycoerythrin/cyanine 5 (PE/Cy5)-labeled streptavidin. Brefeldin A (BFA), ionomycin, and phorbol 12-myristate 13-acetate (PMA) were obtained from Wako Pure Chemical Industries, Ltd. (Osaka, Japan). IntraPrep Permeabilization Reagent was purchased from Beckman Coulter, Inc. (Tokyo, Japan). Guava Viacount Reagent was obtained from Guava Technologies (Hayward, CA, USA). Other chemicals were of the highest analytical grade commercially available.

Preparation of Ro-digest. Ro-digest was prepared according to a previously described procedure $(8)$. In brief, the acid-precipitated protein fraction was suspended in distilled water and boiled. The boiled solution was adjusted to the optimal $\mathrm{pH}$ of Peptidase $\mathrm{R}$ and incubated with the protease for $2 \mathrm{~h}$ at $45^{\circ} \mathrm{C}$. The reaction was stopped by boiling and acidification. The supernatant was collected by centrifugation, lyophilized, and used as Ro-digest.

Mice. Pathogen-free male $\mathrm{C} 3 \mathrm{H} / \mathrm{HeN}$ mice were purchased from Japan SLC, Inc. (Shizuoka, Japan) and housed at $25 \pm 2{ }^{\circ} \mathrm{C}$ with a $12 \mathrm{~h}$-light/dark cycle. The animal experiments were carried out in accordance with the Guidelines for Regulation of Animal Experimentation at Shinshu University, and according to Law No. 105 and Notification No. 6 of the Japanese government.

Cell cultures. Six-week-old male mice were sacrificed by vertebral dislocation, and their spleens were removed aseptically. A single-cell suspension was prepared according to a previously described procedure (9). Cell cultures were set up in duplicate in a 24-well flat-bottomed plate (Sarstedt, Inc., Newton, NC, USA) for cell function analysis. The final concentrations in RPMI1640 medium were as follows: spleen cells, $5 \times 10^{6}$ viable cells $/ \mathrm{mL}$; test peptide, 0 to $100 \mu \mathrm{g} / \mathrm{mL}$; FBS, $5 \%$; penicillin, 100 units $/ \mathrm{mL}$; streptomycin, $100 \mu \mathrm{g} / \mathrm{mL}$. The cell culture was incubated for 48 or $72 \mathrm{~h}$ at $37^{\circ} \mathrm{C}$ in a humidified $5 \% \mathrm{CO}_{2} / 95 \%$ air atmosphere.

The human erythroleukemia cell line K562 (TKG 0210) was obtained from the Cell Resource Center for Biomedical Research (Institute of Development, Aging and Cancer, Tohoku University). K562 cells were grown in RPMI-1640 medium supplemented with 10\% FBS, and the cell density was maintained between $2 \times 10^{5}$ and $2 \times 10^{6}$ cells $/ \mathrm{mL}$.

Cell function analysis. After incubation, cell number was estimated by means of a Guava Personal Cell Function Analyzer (Guava PCA, Guava Technologies). Spleen cells were incubated for $15 \mathrm{~min}$ at $4^{\circ} \mathrm{C}$ with biotin-labeled anti-mouse mAbs specific to CD8 (clone 53-6.7), CD4 (clone RM4-5), or CD11b (clone M1/70), or PE-labeled anti-mouse mAb specific to CD49b (clone DX5), and visualized by incubation with PE/Cy5labeled streptavidin for $15 \mathrm{~min}$ at $4^{\circ} \mathrm{C}$. The cells were analyzed using Guava PCA. In the case of cells having intercellular cytokines, cells were incubated with $40 \mu \mathrm{g} / \mathrm{mL}$ BFA, $4 \mu \mathrm{g} / \mathrm{mL}$ ionomycin, and $40 \mathrm{ng} / \mathrm{mL}$ PMA for $4 \mathrm{~h}$, and then washed with Hanks' Balanced Salt Solutions (HBSS) and fixed in IntraPrep Regent 1 for $15 \mathrm{~min}$ at room temperature. The cells were then washed with HBSS and incubated with IntraPrep Regent 2 for $5 \mathrm{~min}$ at room temperature. Finally, the cells were reacted with PE-labeled anti-mouse mAbs specific to IL-2, IL-4, IL-12, or IFN- $\gamma$, and analyzed using Guava PCA.

To assay cytotoxic activity, a 1-mL spleen cell suspension $\left(1 \times 10^{6}\right.$ cells $\left./ \mathrm{mL}\right)$ was seeded in each well of a 24 well microtiter plate. The K562 was added to the well to give spleen cell/K562 ratios of 1,50 , and 250 . The plate was incubated for $24 \mathrm{~h}$ at $37^{\circ} \mathrm{C}$ in a humidified $5 \% \mathrm{CO}_{2} /$ 95\% air atmosphere, and $380 \mu \mathrm{L}$ Guava Viacount Regent was added to $20 \mu \mathrm{L}$ of each cell suspension. K562 viability was measured by the Guava PCA with Viacount software.

Ion-exchange chromatography. SP-Sepharose column (GE Healthcare Bio-Sciences, Tokyo, Japan) chromatography was performed using an AKTA Prime Chromatography system. The Ro-digest dissolved in $0.02 \mathrm{M}$ sodium phosphate buffer $(\mathrm{PB}, \mathrm{pH} 5.5)$ was subjected to the column equilibrated with $\mathrm{PB}$, and eluted with the same buffer containing 0 to $0.3 \mathrm{M} \mathrm{NaCl}$. The flow rate was $4 \mathrm{~mL} / \mathrm{min}$, the collection volume was $5 \mathrm{~mL} /$ tube, and the absorbance of the effluent was measured at $214 \mathrm{~nm}$ using an Ultrospec 3300 pro UV/Visible spectrophotometer (GE Healthcare Bio-Sciences). The fractions were desalted by ultrafiltration at $4^{\circ} \mathrm{C}$ on an Amicon Ultrafiltration Cell Model 52 (Amicon Corp., Danvers, MA, USA) with an ultrafiltration membrane (nominal molecular weight limit, 1,000 Da, Millipore Corp., Billerica, MA, USA).

Reversed-phase high-performance liquid chromatography (RP-HPLC). The active peptide fraction obtained from SP-Sepharose column chromatography was further purified by means of RP-HPLC consisting of a Shimadzu System 10 instrument (Shimadzu Corp., Kyoto, Japan) with a TSK-Gel ODS-80 TM column (Tosoh, Tokyo, Japan). A mixture of distilled water and acetonitrile containing 0.05\% trifluoroacetic acid (TFA, Wako Pure Chemical Industries, Ltd.) was used as the mobile phase. Elution was carried out with a linear gradient of 5 to $35 \%$ acetonitrile for $5 \mathrm{~min}$ followed by an increase from 35 to $51.4 \%$ acetonitrile for $30 \mathrm{~min}$ at a flow rate of $0.3 \mathrm{~mL} / \mathrm{min}$. The absorbance of the effluent was measured at $214 \mathrm{~nm}$.

Amino acid sequence analysis. The active peptide fraction obtained by RP-HPLC was subjected to tricine- 

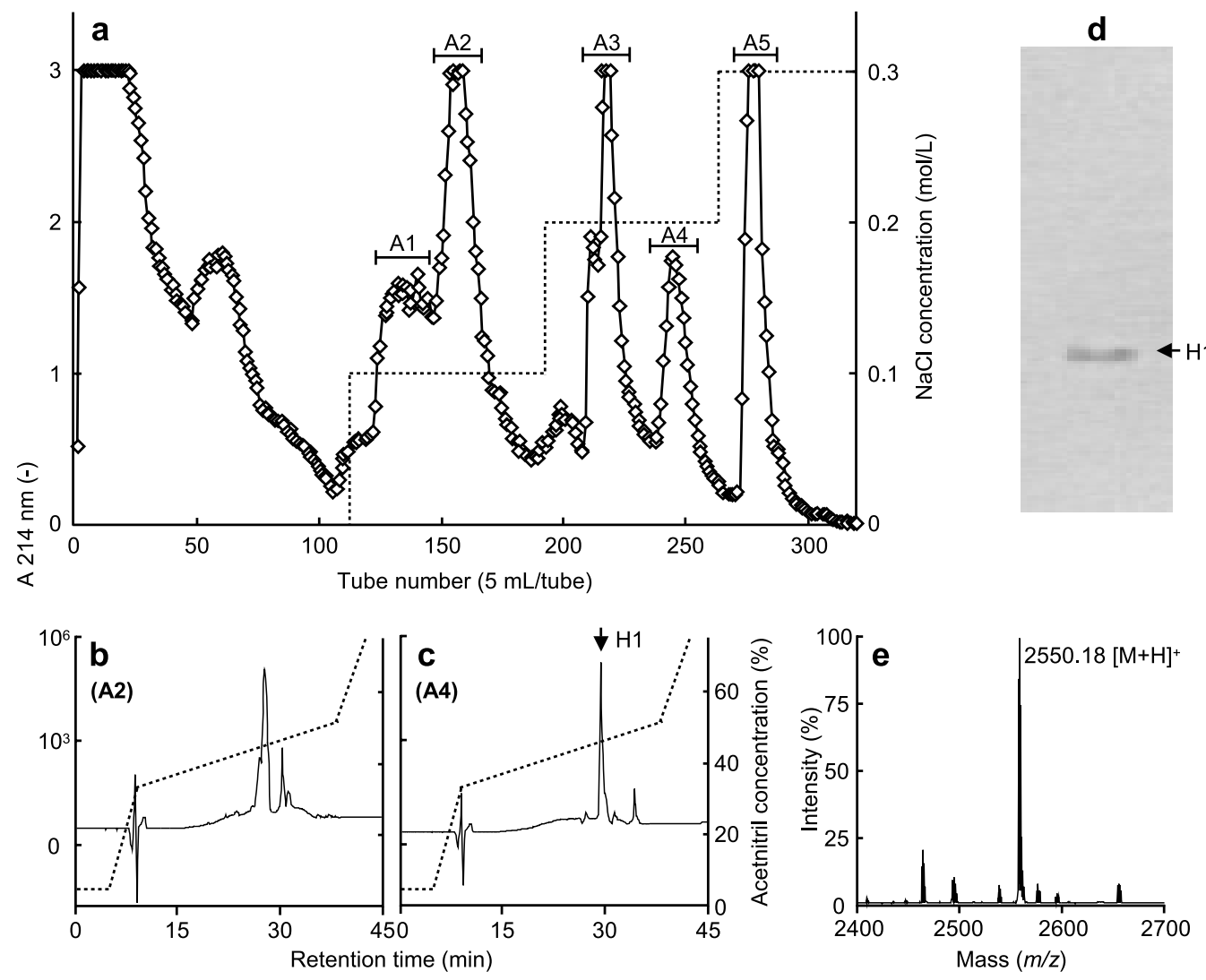

f Amino acid sequence of purified $\mathrm{H} 1$

$(X \cdot \cdots X)_{n}$ - Gly-Gly-Arg-Lys-Gln-Gly-Gln-His-Gln-Gln-Glu-Glu

Amino acid sequence of residues 202 to 225 of glycinin $\mathrm{G} 4$ subunit (16)

Gln202-Gln-Gln-Gln-Gln-Gln-Lys-Ser-His-Gly-Gly-Arg-Lys-Gln-Gly-Gln-His-Gln-Gln-Glu-Glu-Glu-Glu-Glu225

Fig. 1. Purification of an immunostimulating peptide from Ro-digest. (a) A typical elution profile of Ro-digest by SPSepharose column chromatography. Ro-digest dissolved in $0.02 \mathrm{M}$ sodium phosphate buffer (PB) was subjected to a column $(2.6 \times 10 \mathrm{~cm})$ equilibrated with PB and eluted with the same buffer containing different $\mathrm{NaCl}$ concentrations at a flow rate of $4 \mathrm{~mL} / \mathrm{min}$. (b) A typical elution profile of A2 by reversed-phase high-performance liquid chromatography using a TSK-Gel ODS- 80 TM column $(0.6 \times 15 \mathrm{~cm})$. Elution was carried out with a linear gradient of 5 to $35 \%$ acetonitrile for $5 \mathrm{~min}$ followed by an increase from 35 to $51.4 \%$ acetonitrile for $30 \mathrm{~min}$ at a flow rate of $0.3 \mathrm{~mL} / \mathrm{min}$. (c) A typical elution profile of A4 by reversed-phase high-performance liquid chromatography using a TSK-Gel ODS-80 TM column $(0.6 \times 15 \mathrm{~cm})$. Elution was carried out under the same conditions as those of A2. (d) Tricine-SDS-PAGE of the purified H1. (e) MALDI-TOF mass analysis of the purified H1. The major peak is at $m / z 2550.18[\mathrm{M}+\mathrm{H}]^{+}$. (f) Amino acid sequence of the purified $\mathrm{H} 1$.

sodium dodecyl sulfate-polyacrylamide gel electrophoresis (Tricine-SDS-PAGE) in the presence of sodium dodecyl sulfate (10). The buffer system was discontinuous with the following parameters: cathode buffer, $0.1 \mathrm{~m}$ Tris, $0.1 \mathrm{~m}$ tricine, $0.1 \%$ SDS, $\mathrm{pH} 8.25$; anode buffer, $0.2 \mathrm{M}$ Tris-HCl, pH 8.95. The separated peptide was transferred electrophoretically onto a Mini ProBlott Membrane (Applied Biosystems, Foster City, CA, USA). The membrane was stained with Amido Black 10B (Nacalai Tesque, Inc., Kyoto, Japan). A single band was excised and subjected to amino acid sequence analysis by Edman degradation using a Shimadzu PPSQ-21 automated protein sequencer (Shimadzu Corp.).

MALDI-TOF mass spectrometric analysis. MALDI-TOF mass analysis was performed on a Voyager-DE STR (Applied Biosystems) equipped with a nitrogen laser $(337 \mathrm{~nm})$, operating in positive linear mode targeting a mass range from 1,000 to $30,000 \mathrm{~m} / \mathrm{z}$. For the lyo- philized active peptide fraction, $\alpha$-cyano-4-hydroxycinnamic acid dissolved in a $1: 1 \mathrm{v} / \mathrm{v}$ acetonitrile and $0.1 \%$ TFA was used as the matrix.

Chemically synthesized peptides. Two chemically synthesized peptides, QQQQQQKSHGGR and KQGQHQQEEEEE, were obtained from Invitrogen (Carlsbad, CA, USA). The purity of each was confirmed to be above 80\% by RP-HPLC.

Statistical analysis. All data are expressed as means \pm standard deviation (SD) $(n=4)$. The significance of the difference was tested using Student's $t$ test.

\section{RESULTS AND DISCUSSION}

Purification of an immunostimulating peptide

Ro-digest was divided into 5 fractions A1 to A5 by SP-Sepharose column chromatography (Fig. 1a). A2 and A4 significantly increased all immunocompetent cells examined (Table 1). A2 and A4 were separately 
Table 1. Number of immunocompetent cells in mouse spleen cells cultured with Ro-digest fractionated by SP-Sepharose column chromatography.

\begin{tabular}{lcccccc}
\hline & \multicolumn{5}{c}{ Fraction } \\
\cline { 2 - 7 } & Free (control) & A1 & A2 & A3 & A4 & A5 \\
\hline Viable cells $\left(\times 10^{6}\right)$ & $1.318 \pm 0.153$ & $1.139 \pm 0.089$ & $1.658 \pm 0.069^{*}$ & $1.323 \pm 0.081$ & $1.663 \pm 0.140^{*}$ & $1.238 \pm 0.150$ \\
$\mathrm{CD}^{+}\left(\times 10^{3} / 10^{5}\right.$ cells $)$ & $7.150 \pm 0.191$ & $9.700 \pm 0.931^{*}$ & $9.650 \pm 0.574^{*}$ & $9.450 \pm 0.412^{*}$ & $9.200 \pm 0.589^{*}$ & $9.600 \pm 1.095^{*}$ \\
$\mathrm{CD} 49 \mathrm{~b}^{+}\left(\times 10^{3} / 10^{5}\right.$ cells $)$ & $3.150 \pm 0.342$ & $3.825 \pm 0.386$ & $4.200 \pm 0.271^{*}$ & $3.267 \pm 0.462$ & $4.375 \pm 0.568^{*}$ & $3.500 \pm 0.173$ \\
$\mathrm{CD} 11 b^{+}\left(\times 10^{3} / 10^{5}\right.$ cells $)$ & $8.220 \pm 0.497$ & $9.033 \pm 0.603$ & $10.600 \pm 0.245^{*}$ & $8.975 \pm 0.263^{*}$ & $9.075 \pm 0.126^{*}$ & $8.267 \pm 0.289$
\end{tabular}

Spleen cells were cultured with $100 \mu \mathrm{g} / \mathrm{mL}$ of each fraction for $72 \mathrm{~h}$. The data represent means $\pm \operatorname{SD}(n=4)$.

${ }^{*} p$ values of $<0.05$ were considered significantly different from those of the fraction-free culture.

Table 2. Number of immunocompetent cells in mouse spleen cells cultured with purified H1.

\begin{tabular}{|c|c|c|c|c|}
\hline \multirow{2}{*}{$\begin{array}{l}\text { Cells } \\
\left(\times 10^{3} / 10^{5} \text { cells }\right)\end{array}$} & \multicolumn{4}{|c|}{ Peptide concentration $(\mu \mathrm{g} / \mathrm{mL})$} \\
\hline & 0 & 25 & 50 & 100 \\
\hline $\mathrm{CD}^{+}$ & $7.100 \pm 0.557$ & $7.267 \pm 0.550$ & $7.440 \pm 0.673$ & $8.286 \pm 0.241^{*}$ \\
\hline CD11 $b^{+}$ & $7.843 \pm 0.553$ & $8.700 \pm 0.469^{*}$ & $8.617 \pm 0.643^{*}$ & $9.400 \pm 0.253^{*}$ \\
\hline $\mathrm{CD}_{49} \mathrm{~b}^{+}$ & $3.257 \pm 0.172$ & $3.683 \pm 0.549$ & $3.650 \pm 0.418^{*}$ & $4.217 \pm 0.319^{*}$ \\
\hline
\end{tabular}

Spleen cells were cultured with the purified H1 for $72 \mathrm{~h}$. The data represent means \pm SD $(n=4)$.

${ }^{*} p$ values $<0.05$ were considered significantly different from those without the peptide.

recovered and applied to RP-HPLC with a TSK-Gel ODS$80 \mathrm{TM}$ column. Both A2 and A4 eluted as a major peak and several minor peaks (Fig. $1 \mathrm{~b}$ and c). The major peak of A4 (H1) was sharper than that of A2, suggesting that $\mathrm{H} 1$ contains fewer peptides than the major peak of A2. Therefore, H1 was collected and reapplied to the same column until a single peak was obtained. The purified H1 was confirmed to be a single band by Tricine-SDSPAGE (Fig. 1d).

The purified $\mathrm{H} 1$ significantly increased the number of $\mathrm{CD}^{+}, \mathrm{CD} 11 \mathrm{~b}^{+}$, and $\mathrm{CD} 49 \mathrm{~b}^{+}$cells in mouse spleen cell cultures (Table 2). CD8 is a cell-surface antigen expressed on cytotoxic T cells and more weakly on NK cells (11). The importance of $\mathrm{CD}^{+} \mathrm{T}$ cells in the resistance to infection against a challenge with intracellular parasitic infections has been demonstrated (12). CD11b is a typical cell surface antigen of macrophages and DC, and these cells play essential roles in the host innate defense (13). A monoclonal antibody specific to CD49b (DX5) is a typical antibody toward pan-NK cells (14). NK cells also play a critical role in the host innate defense as well as macrophages and DC (15). Taken together, the purified $\mathrm{H} 1$ appears to stimulate the cellular immune system in mouse spleen cell cultures.

The MALDI-TOF mass analysis of the purified H1 showed a major peak at a $\mathrm{m} / \mathrm{z}$ of $2550.18[\mathrm{M}+\mathrm{H}]^{+}$(Fig. 1e). The amino acid sequence analysis by Edman degradation using a Shimadzu PPSQ-21 automated protein sequencer identified 12 residues corresponding to the sequence GGRKQGQHQQEE (Fig. 1f). Although some signals that are considered to derive from amino acid residues were detected before glycine of the $\mathrm{N}$-terminal residue, the sequence analysis did not identify any amino acids before the glycine. Therefore, based on the molecular mass and the sequence, we supposed that $\mathrm{H} 1$ is located at or near the glutamine-rich region 202 to 222 (molecular mass; 2501.18) of the glycinin G4 subunit. N-terminal 6 residues of this region are glutamines (16). Since a glutamine residue in the Nterminal is easily converted to pyroglutamic acid in aqueous solution (17), the pyroglutamic acid is not determined using the present analysis method (18). Thus, we obtained chemically synthesized N-terminal and C-terminal peptides of glycinin G4 subunit, i.e., peptides 202 to 213 (QQQQQQKSHGGR) and 214 to 225 (KQGQHQQEEEEE), and investigated their immunomodulatory activities in mouse spleen cell cultures. Immunomodulatory activity of chemically synthesized glutamine-rich peptides

The effects of 2 chemically synthesized glutaminerich peptides on the number of spleen immunocompetent cells and cytotoxic activity of spleen cells toward the human erythroleukemia cell line K562 were investigated in cell cultures (Table 3, Fig. 2). Both of the synthesized peptides significantly increased the number of IL- $12^{+} \mathrm{CD} 11 \mathrm{~b}^{+}$cells, while only peptide $202-213$ significantly increased the number of $\mathrm{CD} 49 \mathrm{~b}^{+}, \mathrm{IL}^{-} 2^{+} \mathrm{CD} 4^{+}$ and IFN- $\gamma^{+} \mathrm{CD} 4^{+}$cells. In contrast, both peptides showed little influence on the number of $\mathrm{IL}-4^{+} \mathrm{CD} 4^{+}$ cells. The viability of K562 was significantly lower in spleen cell cultures containing peptide 202-213 than in the peptide-free cultures. As described already, $\mathrm{CD} 11 \mathrm{~b}$ and CD49b are cell surface antigens of macrophages/DC and pan-NK cells, respectively $(13,14)$. CD4 is a cell surface antigen of helper T cells (19). IL-12 is a cytokine produced by macrophages and DC (20) 
Table 3. Number of immunocompetent cells in mouse spleen cells cultured with chemically synthesized peptides.

\begin{tabular}{|c|c|c|c|c|c|c|c|}
\hline \multirow{3}{*}{$\begin{array}{l}\text { Cells } \\
\left(\times 10^{3} / 10^{5} \text { cells }\right)\end{array}$} & & \multicolumn{3}{|c|}{ QQQQQQKSHGGR (peptide 202-213) } & \multicolumn{3}{|c|}{ KQGQHQQEEEEE (peptide 214-225) } \\
\hline & \multicolumn{7}{|c|}{ Peptide concentration $(\mu \mathrm{M})$} \\
\hline & 0 & 1 & 5 & 50 & 1 & 5 & 50 \\
\hline $\mathrm{CD}_{49} \mathrm{~b}^{+}$ & $3.450 \pm 0.152$ & $3.267 \pm 0.197$ & $3.433 \pm 0.280$ & $3.867 \pm 0.186^{*}$ & $2.713 \pm 0.230^{*}$ & $2.400 \pm 0.290^{*}$ & $2.950 \pm 0.418$ \\
\hline $\mathrm{IL}-12^{+} \mathrm{CD} 11 \mathrm{~b}^{+}$ & $1.108 \pm 0.094$ & $1.333 \pm 0.116^{*}$ & $1.710 \pm 0.115^{*}$ & $1.777 \pm 0.050^{*}$ & $1.718 \pm 0.159^{*}$ & $1.723 \pm 0.081 *$ & $1.293 \pm 0.194$ \\
\hline $\mathrm{IL}_{-} 2^{+} \mathrm{CD} 4^{+}$ & $1.690 \pm 0.379$ & $2.700 \pm 0.226^{*}$ & $2.258 \pm 0.128^{*}$ & $1.608 \pm 0.230$ & $1.425 \pm 0.201$ & $1.935 \pm 0.209$ & $1.890 \pm 0.114$ \\
\hline IFN- $\gamma^{+} \mathrm{CD} 4^{+}$ & $1.923 \pm 0.175$ & $2.340 \pm 0.128^{*}$ & $2.153 \pm 0.099$ & $1.483 \pm 0.182^{*}$ & $1.843 \pm 0.102$ & $1.785 \pm 0.221$ & $1.685 \pm 0.226$ \\
\hline $\mathrm{IL}_{-} 4^{+} \mathrm{CD} 4^{+}$ & $1.680 \pm 0.085$ & $1.598 \pm 0.181$ & $1.775 \pm 0.120$ & $1.725 \pm 0.150$ & $1.958 \pm 0.283$ & $1.658 \pm 0.268$ & $1.683 \pm 0.327$ \\
\hline
\end{tabular}

In the case of $\mathrm{CD} 49 \mathrm{~b}^{+}$, the spleen cells were cultured for $72 \mathrm{~h}$, and in the case of other cells, the spleen cells were cultured for $48 \mathrm{~h}$. The data represent means \pm SD $(n=4)$.

$* p$ values $<0.05$ were considered significantly different from those without the peptide.

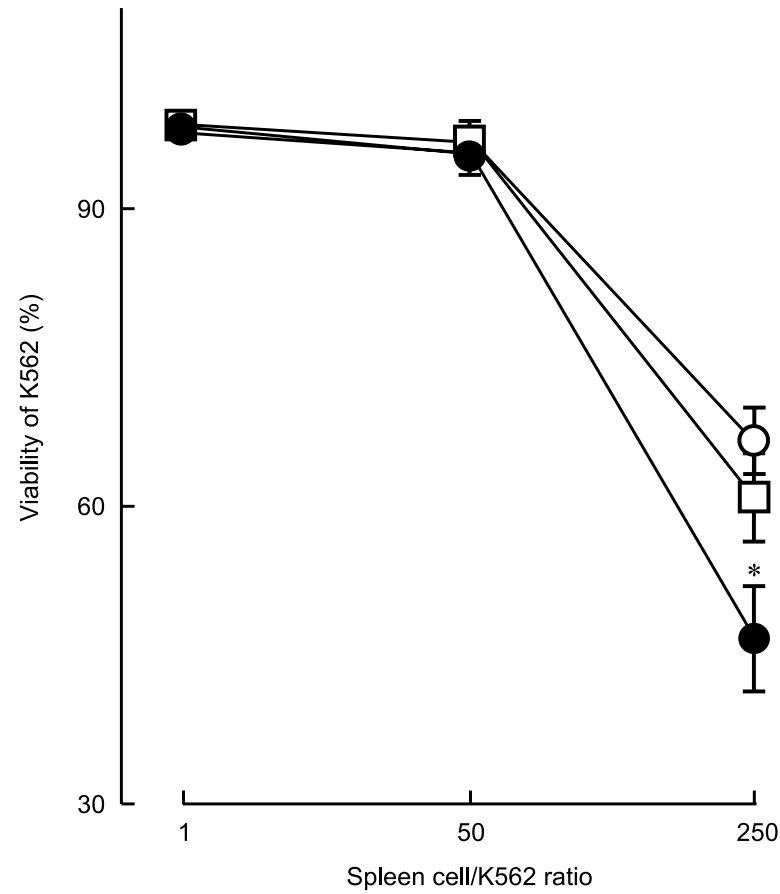

Fig. 2. Effect of chemically synthesized peptides on viability of the human erythroleukemia cell line K562 in mouse spleen cell cultures. Spleen cells were cultured with $50 \mu \mathrm{mol} / \mathrm{L}$ peptide for $72 \mathrm{~h}$. The data represent means \pm SD $(n=4)$. $\bigcirc$, peptide-free; $\bullet$, peptide $202-$ 213; $\square$, peptide $214-225 .{ }^{*} p$ values of $<0.05$ were considered significantly different from those of the peptide-free culture.

and activates NK cells (21), while IFN- $\gamma$ is a cytokine produced by NK and type- 1 helper T (Th1) cells and activates NK cells (15). In addition, IL-2 is one of the major cytokines produced by Th1 cells, and induces the proliferation of NK cells (22). These results indicate that both of the synthesized peptides stimulate macrophages and/or DC, and suggest that peptide 202 to 213 enhances the function of NK cells via the stimulation of IL-12 produced by macrophages and/or DC, and the stimulation of IL- 2 and IFN- $\gamma$ produced by Th1 cells.

Paulsen (23) reported that a synthetic colon peptide, pyroGlu-His-Gly, inhibited the growth of human colon carcinoma cells. Kojima et al. (24) demonstrated that a tripeptide, pyroGlu-Gln-Ala, extracted from a brown marine alga stimulated the cytotoxic activity of peripheral blood lymphocytes toward K562. Moreover, Chu and $\mathrm{Ng}$ (25) found that a glutamine-rich peptide purified from bulbs of the Chinese daffodil stimulated the proliferation of mouse spleen cells, while Horiguchi et al. (26) reported that the oral administration of wheat gluten hydrolysate containing glutamine-rich peptides significantly increased NK cell activity in healthy humans. These demonstrations suggest that the immunomodulatory activity of $\mathrm{H} 1$ found in the present study is attributable to the N-terminal pyroglutamic acid and/ or the glutamine-rich region.

The immune response is divided into two main forms. One is systemic immunity and the other is regional immunity. The former usually concerns the spleen, major lymph nodes, blood and lymph, while the latter mainly relates to the mucosal associated lymphoid tissue (MALT). The MALT has a specialized group in the gastrointestinal tract called the gut associated lymphoid tissue (GALT). The GALT comprises Peyer's patches, mesenteric lymph nodes, lamina propria lymphocytes and intraepithelial lymphocytes (27). The membranous (M) cells are the specialized epithelial cells of the Peyer's patches (28). It is known that food components including bacteria penetrate the mucosal barrier via $\mathrm{M}$ cells, which endocytoses and transports the components into the Peyer's patches, and initiates immune responses (29). In our previous study (8), we demonstrated that the oral administration of Ro-digest stimulated the innate cellular immune systems in mice. The $\mathrm{H} 1$ in the Ro-digest is considered to remain unabsorbed from intestinal tracts because of its higher molecular mass (2549.18). Thus, it is suggested that the H1 may act in the GALT and stimulates the cellular immune system in mice.

In conclusion, we propose that a glutamine-rich region of soybean glycinin may be an effective immunomodulator for preventing infectious diseases. In order to use the glutamine-rich region as the immunomodulator, a further investigation including the determination of effective dosage is now in progress. 


\section{REFERENCES}

1) Ohnuki H, Mizutani A, Otani H. 2006. Oral ingestion of cow's milk immunoglobulin G stimulates some cellular immune systems and suppresses humoral immune responses in mouse. Int Immunopharmacol 6: 13151322.

2) Kuhara T, Yamauchi K, Tamura Y, Okamura H. 2006. Oral administration of lactoferrin increases NK cell activity in mice via increased production of IL-18 and type I IFN in the small intestine. J Interferon Cytokine Res 26: 489-499.

3) Otani H, Kitamura H, Park M, Kihara Y, Oshida T, Kusuhara S, Sawada K. 2000. Enhancement of intestinal IgA levels in piglets by oral administration of a commercially available casein phosphopeptide preparation. Milchwissenschaft 55: 429-432.

4) Otani H, Nakano K, Kawahara T. 2003. Stimulatory effect of a dietary casein phosphopeptide preparation on the mucosal IgA response of mice to orally ingested lipopolysaccharide from Salmonella typhimurium. Biosci Biotechnol Biochem 67: 729-735.

5) Otani H, Wakatsuki S. 2004. Reduction of allergic symptoms in $\mathrm{NC} / \mathrm{Jic}$ Jcl mice given a diet containing a commercially available casein phosphopeptide preparation, CPP-III. Anim Sci J 75: 147-153.

6) Yoshikawa M, Kishi K, Takahashi M, Watanabe A, Miyamura T, Yamazaki M, Chiba H. 1993. Immunostimulating peptide derived from soybean protein. Ann NY Acad Sci 685: 375-376.

7) Tsuruki T, Kishi K, Takahashi M, Tanaka M, Matsukawa T, Yoshikawa M. 2003. Soymetide, an immunostimulating peptide derived from soybean $\beta$-conglycinin, is an fMLP agonist. FEBS Lett 540: 206-210.

8) Egusa S, Otani H. 2009. Soybean protein fraction digested with neutral protease preparation, "Peptidase R", produced by Rhizopus oryzae, stimulates innate cellular immune system in mouse. Int Immunopharmacol 9: 931-936.

9) Otani H, Watanabe T. 2006. Enhancement of immunoglobulin A formation by a casein phosphopeptide, bovine $\beta$-casein (1-28), via modulation of cytokines produced by Th2 type of lymphocytes in mouse spleen cell cultures. Milchwissenschaft 61: 123-126.

10) Schägger H, von Jagow G. 1987. Tricine-sodium dodecyl sulfate-polyacrylamide gel electrophoresis for the separation of proteins in the range from 1 to $100 \mathrm{kDa}$. Anal Biochem 166: 368-379.

11) Zamoyska R. 1994. The CD8 coreceptor revisited: one chain good, two chains better. Immunity 1: 243-246.

12) Rodrigues MM, Boscardin SB, Vasconcelos JR, Hiyane MI, Salay G, Soares IS. 2003. Importance of CD8 T cellmediated immune response during intracellular parasitic infections and its implications for the development of effective vaccines. An Acad Bras Cienc 75: 443-468.

13) Ammon C, Meyer SP, Schwarzfischer L, Krause SW, Andreesen R. 2000. Comparative analysis of integrin expression on monocyte-derived macrophages and monocyte-derived dendritic cells. Immunology 100: 364-369.

14) Arase H, Saito T, Phillips JH, Lanier LL. 2001. The mouse NK cell-associated antigen recognized by DX5 monoclonal antibody is CD49 (a2 integrin, very late antigen-2). J Immunol 167: 1141-1144.

15) Biron CA, Nguyen KB, Pien GC, Cousens LP, SalazarMather TP. 1999. Natural killer cells in antiviral defense: function and regulation by innate cytokine. Ann Rev Immunol 17: 189-220.

16) Nielsen NC, Dickinson CD, Cho TJ, Thanh VH, Scallon BJ, Fischer RL, Sims TL, Drews GN, Goldberg RB. 1989. Characterization of the glycinin gene family in soybean. Plant Cell 1: 313-328.

17) Sato K. 1998. Occurrence of indigestible pyroglutamyl peptides in an enzymatic hydrolysate of wheat gluten prepared on an industrial scale. J Agric Food Chem 46: 3403-3405.

18) Higaki-Sato N, Sato K, Esumi Y, Okumura T, Yoshikawa H, Tanaka-Kuwajima C, Kurata A, Kotaru M, Kawabata M, Nakamura Y, Ohtsuki K. 2003. Isolation and identification of indigestible pyroglutamyl peptides in an enzymatic hydrolysate of wheat gluten prepared on an industrial scale. J Agric Food Chem 51: 8-13.

19) Sleckman BP, Shin J, Igras VE, Collins TL, Strominger JL, Burakoff SJ. 1992. Disruption of the CD4-p56lck complex is required for rapid internalization of CD4. Proc Natl Acad Sci USA 15: 7566-7570.

20) Dhodapkar KM, Kaufman JL, Ehlers M, Banerjee DK, Bonvini E. 2005. Selective blockade of inhibitory Fc $\gamma$ receptor enables human dendritic cell maturation with Il-12p70 production and immunity to antibody-coated tumor cells. PNAS 102: 2910-2915.

21) Rodella L, Rezzani R, Zauli G, Mariani AR, Rizzoli R, Vitale M. 1998. Apoptosis induced by NK cells is modulated by the NK-active cytokines IL-2 and IL-12. Int Immunol 10: 719-725.

22) Feron DT, Locksley RM. 1996. The instructive role of innate immunity in the acquired immune response. Science 272: 50-54.

23) Paulsen JE. 1993. The synthetic colon peptide pyroGluHis-GlyOH inhibits growth of human colon carcinoma cell (HT-29) transplanted subcutaneously into athymic mice. Carcinogenesis 14: 1719-1721.

24) Kojima T, Kolike A, Yamamoto S, Kanemitus T, Miwa M, Kamei H, Kondo T, Iwata T. 1993. Eisenin (L-pyroGlu-LGln-L-Ala), a new biological response modifier. J Immunother 13: 36-62.

25) Chu KT, Ng TB. 2004. First report of a glutamine-rich antifungal peptide with immunomodulatory and antiproliferative activities from family Amaryllidaceae. Biochem Biophys Res Commun 325: 167-173.

26) Horiguchi N, Horiguchi H, Suzuki Y. 2005. Effect of wheat gluten hydrolysate on the immune system in healthy human subjects. Biosci Biotechnol Biochem 69: 2445-2449.

27) Iwasaki A, Kelsall BL. 2000. Localization of distinct Peyer's patch dendritic cell subsets and their recruitment by chemokines macrophage inflammatory protein (MIP)-3alpha, MIP-3beta, and secondary lymphoid organ chemokine. J Exp Med 17: 1381-1394.

28) Wolf JL, Bye WA. 1984. The membranous epithelial (M) cell and the mucosal immune system. Annu Rev Med 35: 95-112.

29) Mowat AM. 2003. Anatomical basis of tolerance and immunity to intestinal antigens. Nat Rev Immunol 3: 331-341. 